九州大学学術情報リポジトリ

Kyushu University Institutional Repository

\title{
Relationship Between Plant Bioelectrical Potential and Water Consumption Environment
}

\section{Yuge, Kozue}

Laboratory of Water Resources Engineering, Division of Rural Engineering, Department of Bioresource, Faculty of Agriculture, Ehime University I JSPS Research Fellow

Hamagami, Kunihiko

Laboratory of Water Resources Engineering, Division of Rural Engineering, Department of Bioresource, Faculty of Agriculture, Ehime University | JSPS Research Fellow

Shinogi, Yoshiyuki

Laboratory of Water Resources Engineering, Division of Rural Engineering, Department of Bioresource, Faculty of Agriculture, Ehime University | JSPS Research Fellow

https://doi.org/10.5109/18853

出版情報: 九州大学大学院農学研究院紀要. 55 (2)，pp. 365-370，2010-10-29. Faculty of Agriculture, Kyushu University

バージョン：

権利関係 : 


\title{
Relationship Between Plant Bioelectrical Potential and Water Consumption Environment
}

\section{Kozue YUGE*, Kunihiko HAMAGAMI ${ }^{1}$ and Yoshiyuki SHINOGI}

\author{
Laboratory of Irrigation and Water Utilization, Division of Bioproduction Environmental Sciences, \\ Department of Agro-environmental Sciences, Faculty of Agriculture, \\ Kyushu University, Fukuoka 812-8581, Japan \\ (Received June 28, 2010 and accepted July 9, 2010)
}

\begin{abstract}
The objective of this study is clarification of the relationship between plant bioelectrical potential and water consumption environment, including transpiration, irrigation, and water stress. Experiments are conducted to clarify the relationship; to extract the plant bioelectrical potential, spectral analysis is introduced. The result indicates that when the transpiration rate is high, the power spectrum is broader. The experimental result indicates that plant bioelectrical potential fluctuates after several seconds of irrigation. To clarify the difference between the plant bioelectrical potential before and after irrigation, the power spectra before and after irrigation are estimated. The results indicate that power after irrigation is higher than power before irrigation. After irrigation, the power spectrum from $0.01 \mathrm{~Hz}$ to $0.2 \mathrm{~Hz}$ is predominant. To extract the plant bioelectrical potential under water stress and non-stress conditions, the power spectrum analysis is conducted. The results indicate that the power spectrum under the non-stress condition is relatively stable and amplitude is small. On the other hand, the amplitude of the power spectrum is relatively large, and the power spectrum from $0.05 \mathrm{~Hz}$ to $0.15 \mathrm{~Hz}$ is predominant under water stress condition. The power spectrum analysis clarified the difference. The plant reaction to the change of the water consumption environment can be evaluated using the plant bioelectrical potential.
\end{abstract}

\section{INTRODUCTION}

Plants react sensitively to changes in their environment. Plant bioelectrical potential is used to evaluate the plant physiological phenomenon and reactions to such changes. Various studies about the relationship between the plant bioelectrical potential and the surrounding environment were conducted. Roblin and Bonnemain (1985) reported the propagation of the bioelectrical potential of bean induced by wounding. Inagaki et al. (1996) and Yanagibashi et al. (2004, 2005, and 2006) studied the effect of light environment on the plant bioelectrical potential. Hasegawa et al. (2004) and Nakayama et al. (2008) clarified that the plant reaction to air pollution can be evaluated using the plant bioelectrical potential. These studies highlighted the effects of physiological phenomena, including photosynthesis and purification of air pollution, on the plant bioelectrical potential. However, the relationship between plant bioelectrical potential and water consumption, one of the most important physiological phenomena, has not been evaluated.

Water consumption in crop fields has been studied by many researchers. Yuge et al. (2005) established a method for quantifying soil surface evaporation considering the micro-advective effect in micro-irrigated fields. However, plant reaction to irrigation, evapotranspiration, and water stress is unclear.

The objective of this study is clarification of the relationship between plant bioelectrical potential and water consumption environment, including transpiration, irri-

${ }^{1}$ Laboratory of Water Resources Engineering, Division of Rural Engineering, Department of Bioresource, Faculty of Agriculture, Ehime University, JSPS Research Fellow

* Corresponding author (E-mail: yuge@bpes.kyushu-u.ac.jp) gation, and water stress. Experiments are conducted to clarify the relationship. To extract the bioelectrical potential, spectral analysis is introduced.

\section{MATERIALS AND METHODS}

Figure 1 shows the measurement system of the plant bioelectrical potential. The test plant used in this study is Datura metel. A reference electrode and a glass electrode immersed in $\mathrm{KCl}$ solution are used for measuring the plant bioelectrical potential. The glass electrode is connected with stainless needles through $10 \mathrm{mM} \mathrm{KCl}$ solution, and the stainless needles are inserted into the plant stem. The reference electrode is set in the soil near the plant root. The plant bioelectrical potential is measured every second.

The transpiration is measured at 3 pots using the sap flow system (Flow4, Dynamax) to clarify the rela-

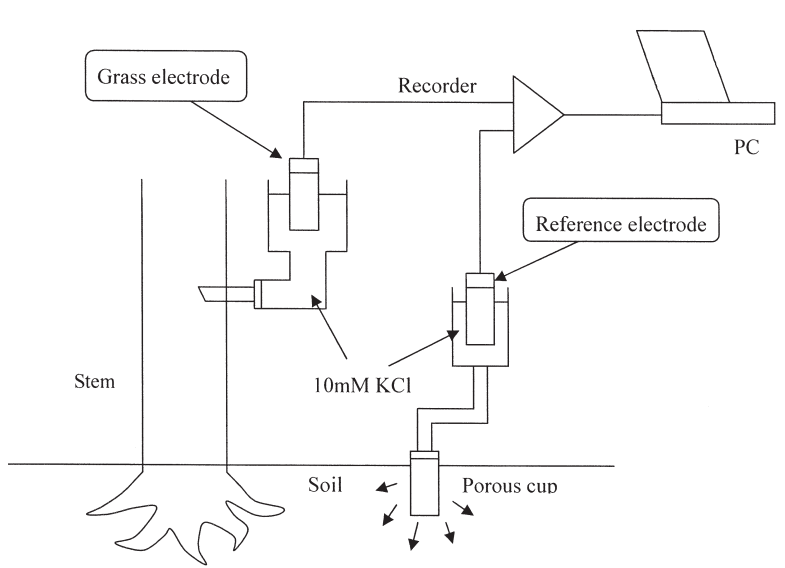

Fig. 1. Measurement system for the plant bioelectrical potential. 
tionship between the plant bioelectrical potential and the water consumption condition. Additionally, to evaluate the effect of water stress on the bioelectrical potential, sucrose solution is irrigated to test plants to generate the water stress condition. The bioelectrical potentials of sucrose treatment samples are compared with the nontreatment samples.

\section{RELATIONSHIP BETWEEN TRANSPIRATION RATE AND PLANT BIOELECTRICAL POTENTIAL}

Figure 2 shows the temporal changes of plant bioelectrical potential on 1st Jan. and 5th Jan. On 1st Jan., the transpiration is very low, while transpiration rate observed on 5th Jan. is high. The plant bioelectrical potential on 5th Jan. is also relatively high, compared with the data obtained on 1st Jan. Figure 3 shows the relationship between the transpiration rate and the plant bioelectrical potential. The bioelectrical potential is represented as the moving average of one hour. On 1st Jan., the transpiration rate is low all day, and the bioelectrical potential is constant. The plant bioelectrical potential decreases as the transpiration increases on 5th Jan.

It was difficult to distinguish the differences in the waveforms of the original data of the bioelectrical potential. To clarify the relationship between the plant bioelectrical potential and the transpiration rate, spectral analysis is introduced. The autocorrelation of the plant bioelectrical potential is estimated as follows:

$$
R_{j}=\frac{1}{N} \sum_{m=0}^{N-1} x_{m} x_{m+j}
$$

where $N$ is the number of data and $R_{j}$ is the autocorrelation of data $x$. The power spectrum $G_{k}$ is estimated using Fourier transform as follows:

$$
G_{k}=\frac{1}{N} \sum_{j=0}^{N-1} R_{j} e^{-i(2 \pi k j / N)}
$$

Smoothing of the power spectrum is conducted by Hanning wind, a digital filter, as follows:

$$
\bar{G}_{k}=0.25 G_{k-1}+0.50 G_{k}+0.25 G_{k+1}
$$

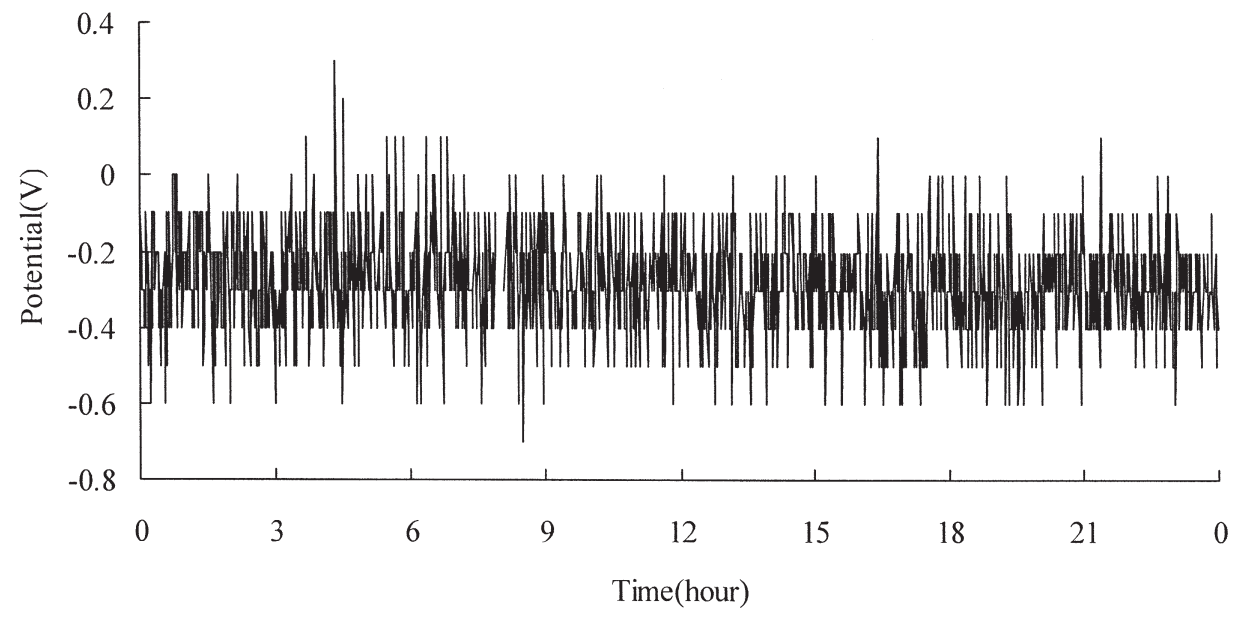

(a) 1st Jan.

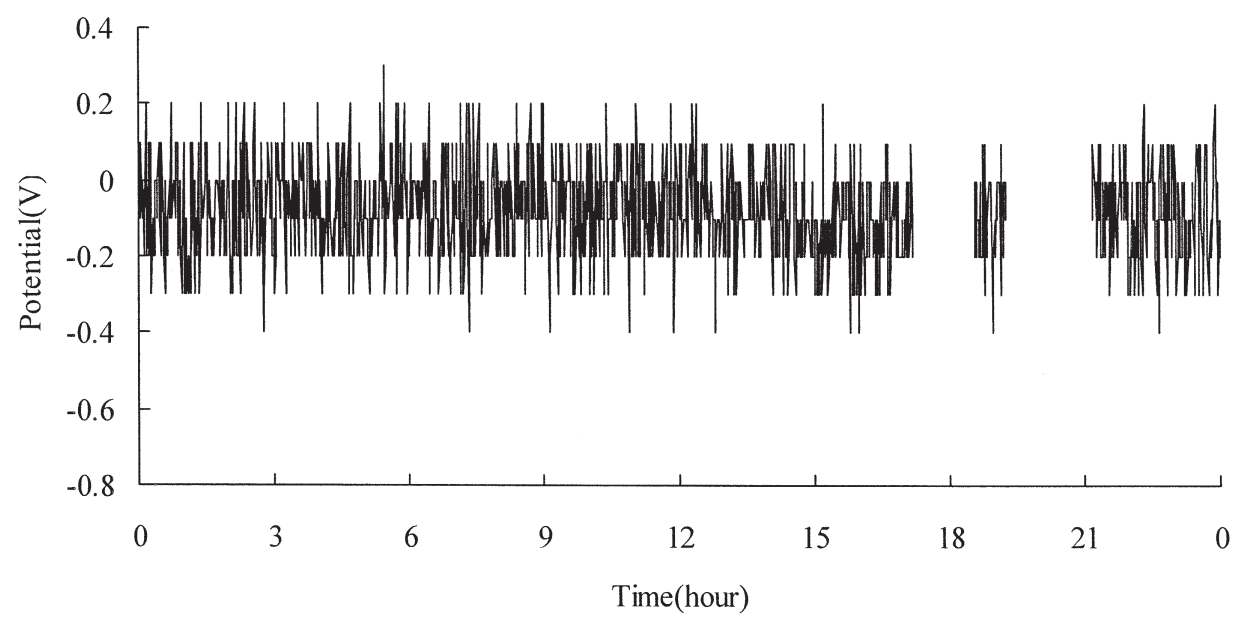

(b) 5th Jan

Fig. 2. Temporal changes of the plant bioelectrical potential. 


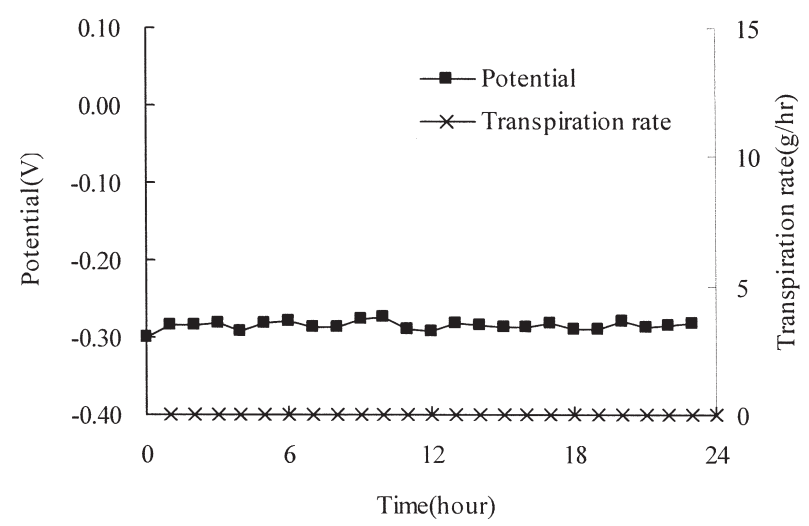

(a) 1st Jan.

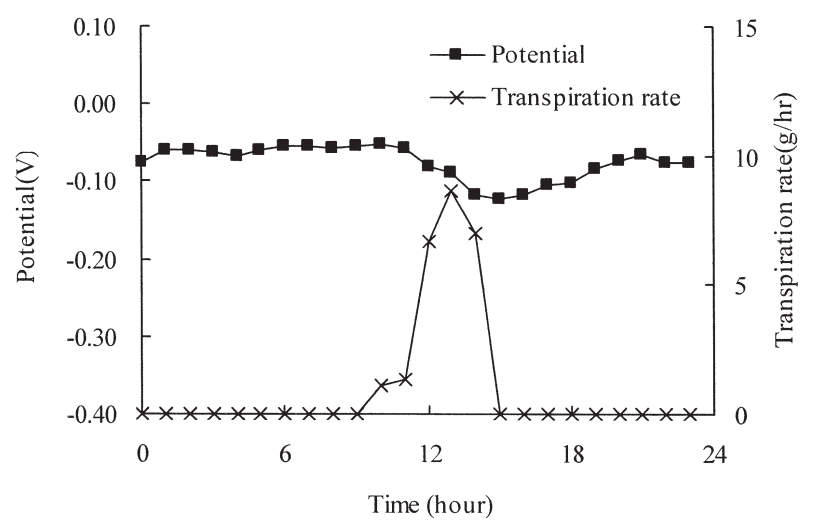

(b) 5th Jan.

Fig. 3. Relationship between transpiration rate and plant bioelectrical potential moving.

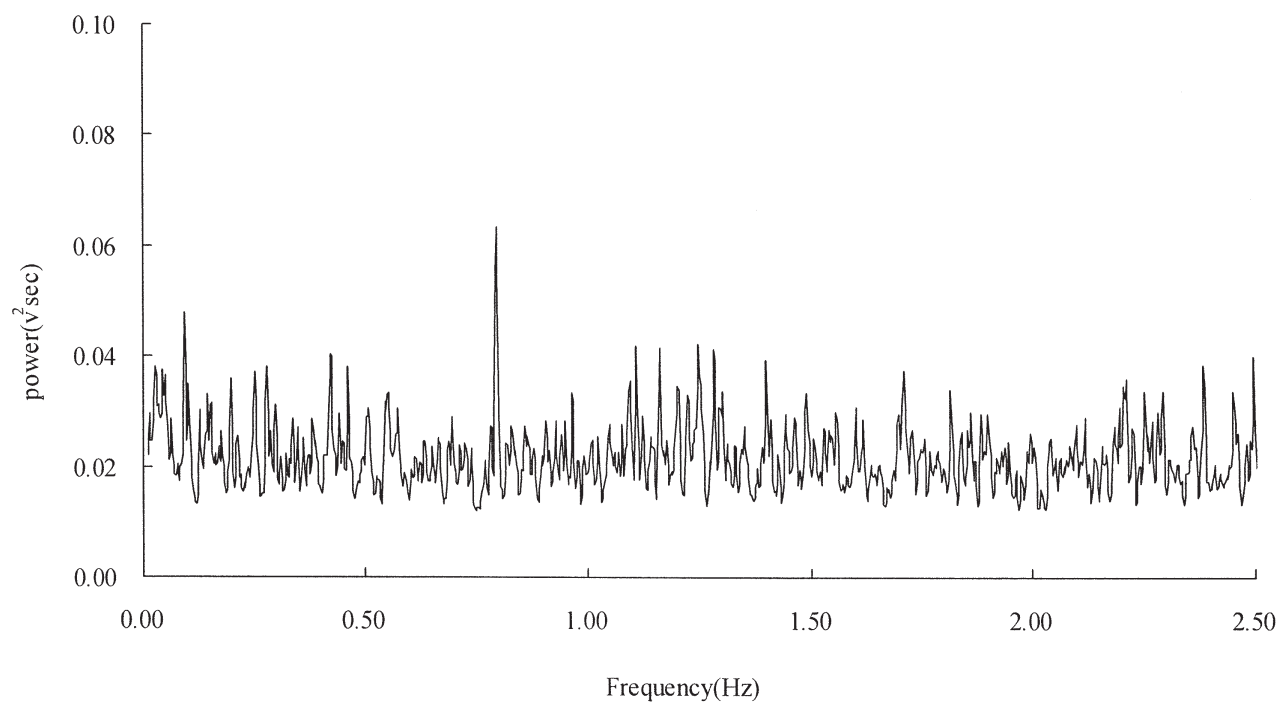

(a) 1st Jan.

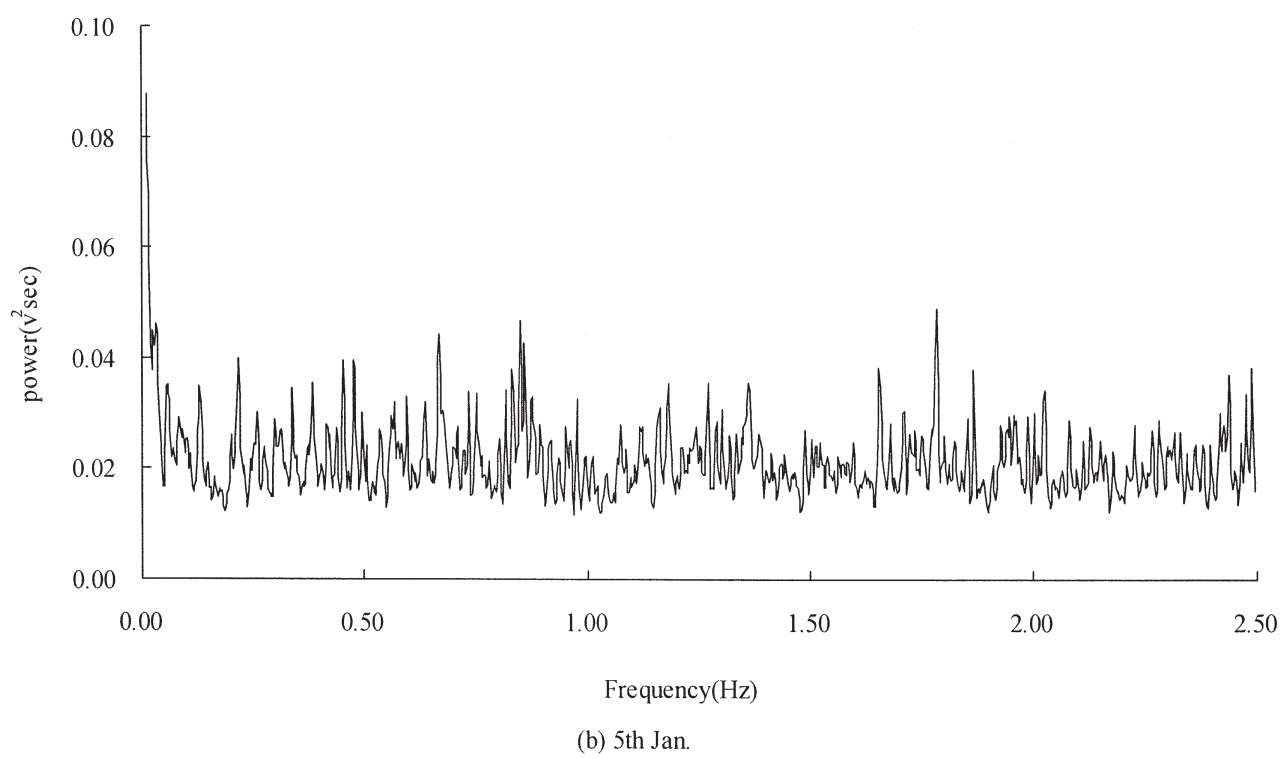

Fig. 4. Power spectra of the plant bioelectrical potential compared with the transpiration rate. 
Figure 4 shows the power spectra estimated using the data for all day. The power spectrum of 5th Jan., when the transpiration rate is high, is larger than the value of 1st Jan. The spectral analysis extracts the variation in the plant bioelectrical potential.

\section{RELATIONSHIP BETWEEN IRRIGATION AND PLANT BIOELECTRICAL POTENTIAL}

Figure 5 shows the plant bioelectrical potential when irrigation is conducted. The plant bioelectrical potential fluctuates after several seconds of irrigation. This fluctuation is observed in several tests, and it is considered that the time lag is brought the infiltration of irrigation water into the soil. The difference in the plant bioelectrical potential before and after irrigation is not clear. The power spectra before and after irrigation are estimated, as shown in Fig. 6. The power after irrigation is higher than the power before irrigation. After irrigation, the power spectrum from $0.01 \mathrm{~Hz}$ to $0.2 \mathrm{~Hz}$ is predominant. While it is difficult to evaluate the difference in the plant bioelectrical potential before and after irrigation, the difference is clarified using power spectrum analysis.

\section{RELATIONSHIP BETWEEN WATER STRESS AND PLANT BIOELECTRICAL POTENTIAL}

The difference in the plant bioelectrical potential between the water stress condition and non-stress condition is shown in Fig. 7. In this study, sucrose solution is irrigated to test plants to generate the water stress condition. The plant bioelectrical potential fluctuates after several seconds of supplying the sucrose solution. The fluctuation after supplying the sucrose solution is relatively wide compared with the conditions before supplying the sucrose solution. To extract the plant bioelectrical potential, power spectrum analysis is conducted. The data for 30 minutes under the water stress and non-stress

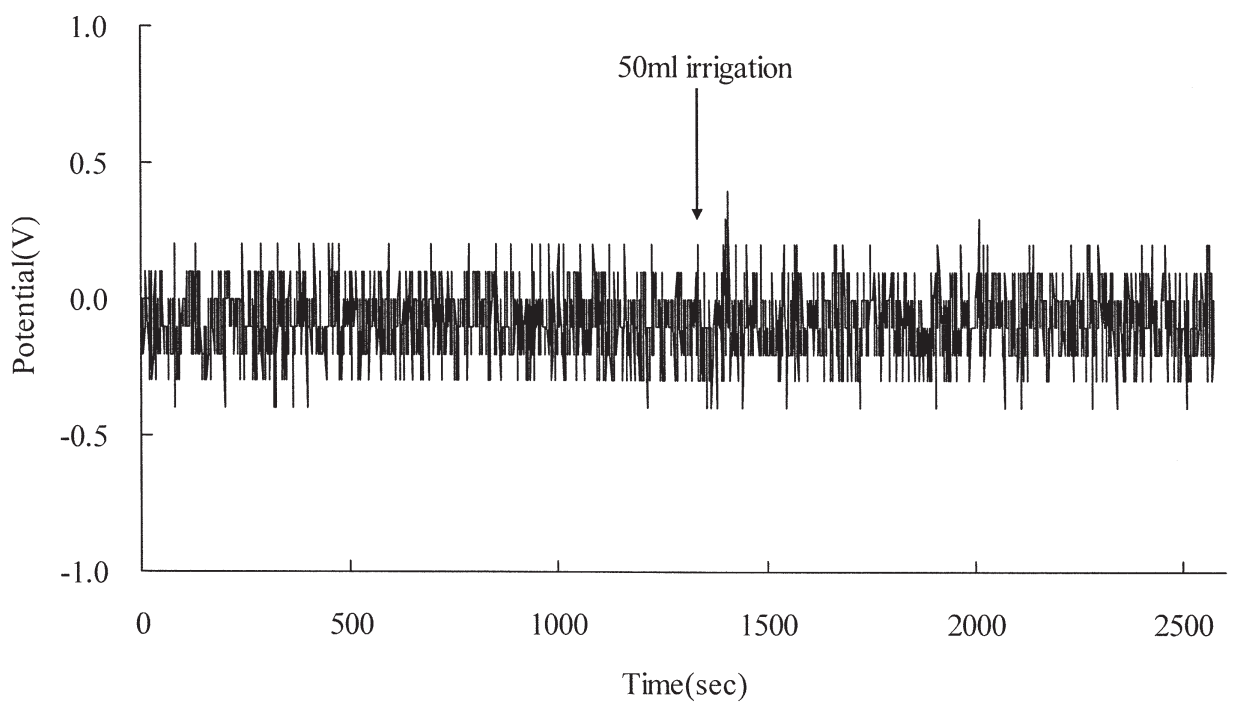

Fig. 5. Temporal change of the plant bioelectrical potential when irrigation is conducted.

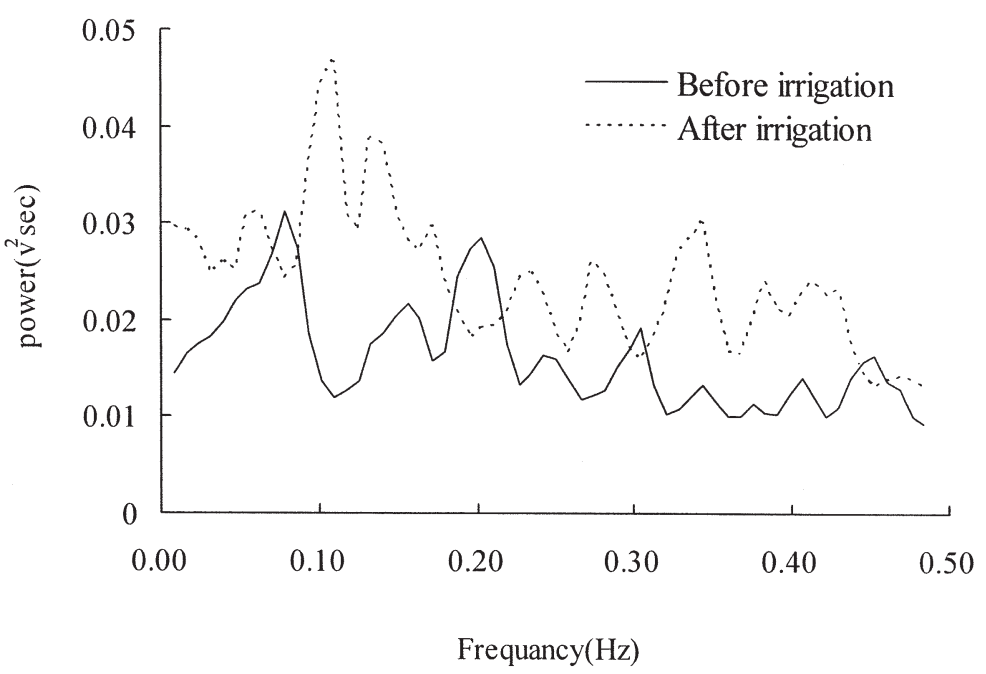

Fig. 6. Power spectra of the plant bioelectrical potential before and after irrigation. 


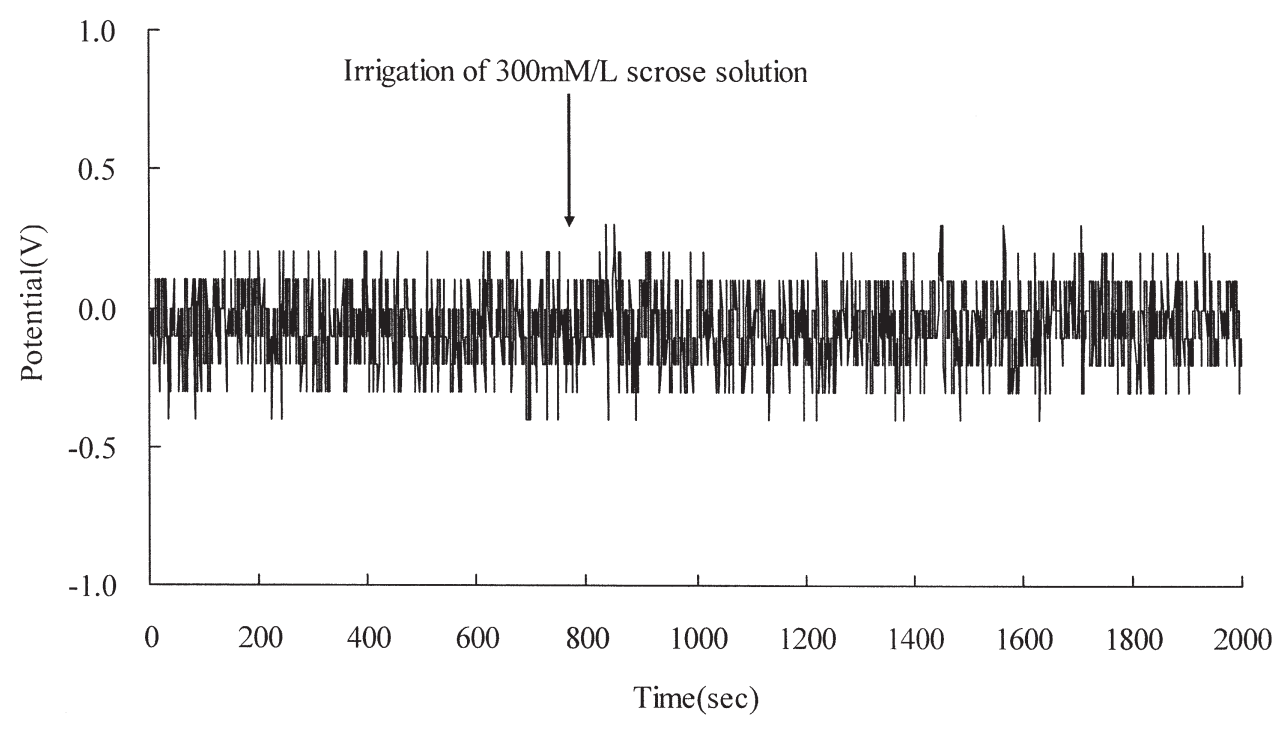

Fig. 7. Temporal change of the plant bioelectrical potential between water stress and non-stress conditions.

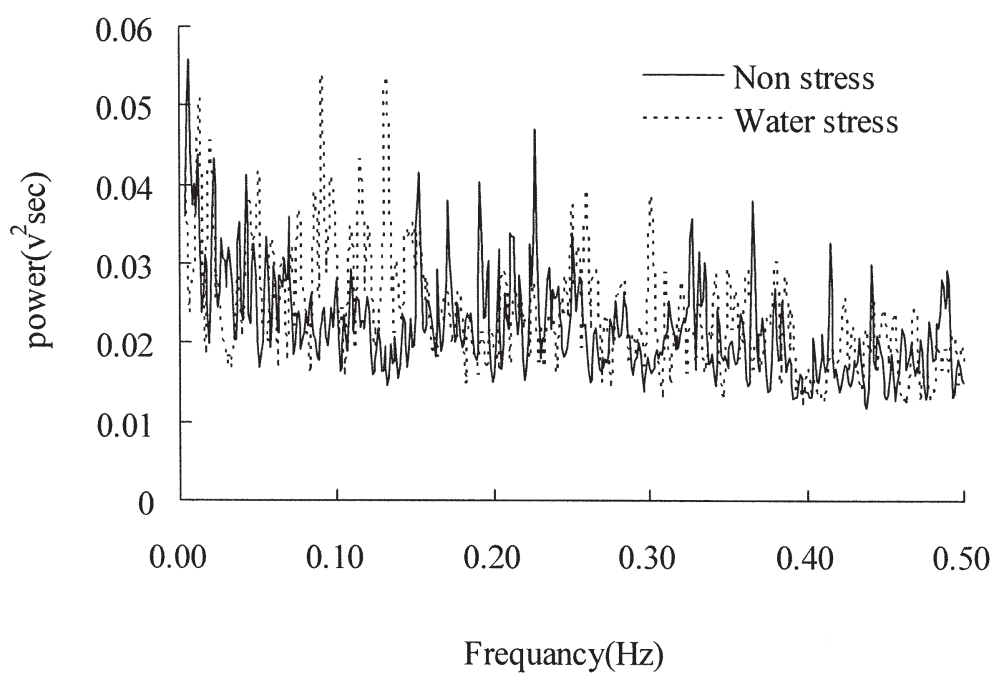

Fig. 8. Power spectra of the plant bioelectrical potential under water stress and non-stress conditions.

conditions is used for the analysis. The results (Fig. 8) indicate that the power spectrum under non-stress condition is relatively stable and amplitude is small. On the other hand, the amplitude of the power spectrum is relatively large, and the power spectrum from $0.05 \mathrm{~Hz}$ to $0.15 \mathrm{~Hz}$ is predominant.

\section{CONCLUSIONS}

To clarify the relationship between the plant bioelectrical potential and the water consumption environment, the plant bioelectrical potential and transpiration rate are measured. The plant bioelectrical potential decreases as the transpiration increases. Determining the differences among the waveforms of the original data of the bioelectrical potential is difficult because the plant bioelectrical potential fluctuates widely. To clarify the relationship between the plant bioelectrical potential and the water consumption condition, spectral analysis is introduced. The results indicate that the power spectrum is greater when the transpiration rate is higher.

The experimental results indicate that the plant bioelectrical potential fluctuates after several second of irrigation. It is considered that the time lag is brought the infiltration of irrigation water into the soil. To clarify the difference in the plant bioelectrical potential before and after irrigation, the power spectra both before and after irrigation are estimated. The results indicate that the power after irrigation is higher than the power before irrigation. After irrigation, the power spectrum from $0.01 \mathrm{~Hz}$ to $0.2 \mathrm{~Hz}$ is predominant.

The difference in the plant bioelectrical potential between the water stress condition and non-stress condition is demonstrated. To extract the plant bioelectrical potential under water stress and non-stress conditions, the power spectrum analysis is conducted. The 
results indicate that the power spectrum under nonstress conditions is relatively stable and the amplitude is small. On the other hand, the amplitude of the power spectrum is relatively large, and the power spectrum from $0.05 \mathrm{~Hz}$ to $0.15 \mathrm{~Hz}$ is predominant.

In conclusion, it is difficult to evaluate the relationship between the plant bioelectrical potential and the water consumption environment, including the transpiration rate, irrigation, and water stress. However, power spectrum analysis can clarify the difference. Plant reactions to the change of the water consumption environment can be evaluated using the plant bioelectrical potential.

\section{REFERENCES}

Hasegawa Y., S. Asada, T. Katsube and T. Ikeguchi 2004 Analysis of Bioelectrical Potential When Plant Purifies Air Pollution. IEICE transactions on electronics, E87-C (12): 2093-2098

Inagaki, Y., M. Kawakubo, S. Ito, and T. Karasuno 1996 1/f fluctuation characteristics of plant bio-electric potentials. Bulletin of Daido Institute of Technology, 32: 107-114 (in
Japanese with English abstract)

Roblin, G., and J. Bonnemain 1985 Propagation in Vicia faba stem of a potential variation induced by wounding. Plant and cell physiology, 26(7): 1273-1283

Yanagibashi H., D. Matsuoka, J. Hirama, and T. Miyamoto 2006 Effects of Light Intensity on the Bio-Electric Potential and the Morphogenetic Properties of Pholiota nameko. Journal of Society of High Technology in Agriculture, 18(2): 167172 (in Japanese with English abstract)

Yanagibashi H., D. Matsuoka, J. Hirama, T. Miyamoto, K. Nishibori, and Y. Ohdaira 2005 Effects of Wavelength of Light Stimuli on the Bio-Electric Potential and the Morphogenetic Properties of Pleurotus eryngii. Journal of Society of High Technology in Agriculture, 17(4): 175-181 (in Japanese with English abstract)

Yanagibashi H., D. Matsuoka, J. Hirama, T. Miyamoto, K. Nishibori, Y. Ohdaira 2004 Bio-Electric Potential of Grifola frondosa under Light Stimuli. (Part 4): Characteristics of Rhythmic Fluctuation of the Fruit Body and the Primordium. Journal of Society of High Technology in Agriculture, 16(4): 193-197 (in Japanese with English abstract)

Yuge K., T. Haraguchi, Y. Nakano, M. Kuroda and M. Anan 2005 Quantification of soil surface evaporation under micro-scale advection in drip-irrigated fields. Paddy and Water Environment, 3(1): 5-12 